The Version of Record of this manuscript has been published and is available in Aging \& Mental Health (2016) http://www.tandfonline.com/doi/full/10.1080/13607863.2016.1181712

\title{
Same-Sex Partner Bereavement in Older Women: An Interpretative Phenomenological
}

\section{Analysis}

\author{
Charlotte F A Ingham ${ }^{\mathrm{a} *}$, Fiona J R Eccles ${ }^{\mathrm{a}}$, Jocelyn R Armitage ${ }^{\mathrm{a}}$ \& Craig D Murray ${ }^{\mathrm{a}}$

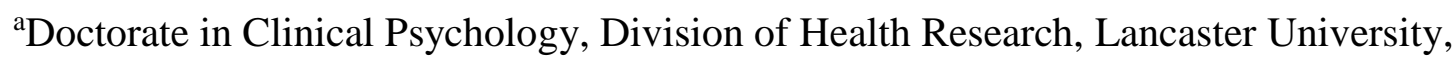 \\ Lancaster, LA1 4YF
}

*Corresponding author. Email: charlotteingham@me.com

Acknowledgements: We would like to thank the women who kindly offered to take part in this research. A further thank you is offered to Ste Weatherhead and Kathryn Almack for their helpful and encouraging feedback.

Word Count: 6091 (excluding cover page, references and table) 


\section{Same-Sex Partner Bereavement in Older Women: An Interpretative Phenomenological}

\section{Analysis}

Objectives: Due to the lack of existing literature, the current research explored experiences of samesex partner bereavement in women over the age of 60.

Method: Semi-structured interviews were conducted with eight women. Transcripts were analysed using interpretative phenomenological analysis (IPA).

Results: Three themes were identified which elaborated the experiences of older women who had lost a same-sex partner: (i) being left alone encapsulated feelings of isolation and exclusion; (ii) navigating visibility centred on how homophobia led to a lack of recognition of the women's grief; and (iii) finding new places to be authentic related women's need for new relationships in which they could be themselves. The findings indicate that existing models of partner bereavement may provide useful frameworks when seeking to understand the experiences of older women who have lost their same-sex partners.

Conclusion: The findings indicate that in addition to the experiences of partner bereavement noted in research with heterosexual widows, older women who lose same-sex partners may face particular challenges, which can impact upon psychological wellbeing and adjustment to loss. These challenges appear to result from past and current homophobic and heterosexist attitudes within UK culture. A range of interventions at individual, group, health service, and societal levels may be beneficial in improving the psychological wellbeing of older women who lose a same-sex partner.

Keywords: bereavement, psychological wellbeing, LGBT, ageing, qualitative 


\section{Introduction}

As people age, they are at increased risk of experiencing significant and numerous losses, including losing their partner (Moss, Moss \& Hansson, 2001). Although bereavement-related distress is often overlooked in later life, due to the view that bereavement is inevitable and natural (Moss et al., 2001), it may lead to declines in mental health, social functioning (Bennett, 1997; 1998) and physical health (Stroebe, Schut \& Stroebe, 2007) as well as increased mortality. Further understanding partner loss in later life is therefore important, particularly given the ageing population.

There are a number of theories that purport to explain the 'usual' stages, tasks or phases that may lead to adjustment following bereavement (Bowlby, 1980; Gillies \& Neimeyer, 2006; Kübler-Ross, 1975; Worden, 2009). One model particularly useful for conceptualising experiences of grief is the dual process model of coping (Stroebe \& Schut, 1999). This model describes two oscillating processes of coping with grief: loss and restoration. Loss-orientation refers to concentrating on and processing the pain of the loss; what Freud had previously termed 'grief work' (1917/1957). Whereas restoration-orientation involves a focus on reorienting oneself to a life without the lost person. It is suggested that bereaved individuals may oscillate between these two processes, which leads to adaptation to loss (Stroebe \& Schut, 2010). It is now widely acknowledged that adaptation to loss is likely non-linear and fluid, and therefore difficult to determine what constitutes 'maladaptation' (Worden, 1996).

A further theory relevant to consider is that of 'disenfranchised grief ' (Doka, 1989). This may occur when grief 'is not or cannot be openly acknowledged, publicly mourned or socially supported' (Doka, 1989, p. 4). Doka divided these types of grief into three themes: (i) unrecognised relationships, such as those kept secret; (ii) unrecognised losses, for example perinatal deaths; and (iii) unrecognised grievers, such as young children, older people or 
anyone believed to be unable to grieve (see Murray, Parkes \& Prigerson, 2010). In such cases, intervention from health and social care services may be beneficial to support the process of adjustment (Bergman \& Haley, 2009) and allow the losses to be acknowledged.

Existing literature provides valuable insights into bereavement experiences in later life (Bennett \& Vidal-Hall, 2000; Parkes, 1970), and the effect of ageing on adjustment is complex (Hansson \& Stroebe, 2007). Although ageing and its associated life experiences can help people develop resilience and adjustment (Bellamy, Gott, Waterworth, McLean \& Kerse, 2014), older people may also have difficulty in adjusting to life as a single person, finding it challenging to re-learn skills or redefine their identity (Naef, Ward, Mahrer-Imhof \& Grande, 2013). Having supportive social networks may serve to support the bereavement process in older widow(er)s (Lobb et al., 2010) in both the loss-oriented and restorationoriented tasks of grieving (Stroebe \& Schut, 2010). However, support networks also often become depleted in later life (Hawthorne, 2006).

In addition, much of this research focuses on the experiences of heterosexual widow(er)s, while much less research has explored the experiences of partner loss in the lesbian, gay, bisexual or transgender (LGBT) population. Within the UK, as recently as the last century non-heterosexuality incurred the death penalty, forced conversion treatment and widespread discrimination (Herek, 2004). Despite recent changes to the law, including the introduction of civil partnerships and legal same-sex marriage in the UK, homophobia and heterosexism persist (Monk, 2011). Given this context, experiences of partner loss may differ between older LGBT and heterosexual individuals.

Stigma may mean that the grief of same-sex partner loss is disenfranchised (Almack, Seymour \& Bellamy, 2010; Jenkins, Edmundson, Averett \& Yoon, 2014), which may disrupt adjustment to loss (Doka, 1989). Older LGBT individuals may also lack family support, due 
to having lost parents, and having children less often than heterosexual couples (Musingarimi, 2008), therefore relying more heavily on support from friends (Almack et al., 2010). Following same-sex partner bereavement, older women may be at considerable risk of social isolation, related to the loss of the social support previously received from their partner, exclusion from their partner's family following the loss, and disconnection from LGBT community (Almack et al., 2010; Bent \& Magilvy, 2006; Fenge, 2014; Jenkins et al., 2014). Fear of discrimination may also create barriers for these women in seeking support from health and social care services following bereavement (Fish, 2010).

Although many older people adjust to the loss of a partner without needing to engage in formal support services (Stroebe, Schut \& Stroebe, 2005), health and social care professionals can benefit from an awareness of the particular difficulties that this group may face if they are to effectively support those who do come into contact with services. Given the potential implications for the wellbeing of older same-sex oriented women who have lost a partner, the current research aimed to explore these women's personal experiences of loss and how they made sense of these, with a particular focus on the experiences that are novel and specific to this group.

While it is agreed that there is political value in lesbian, gay, bisexual and transgender individuals uniting for the purposes of furthering the LGBT movement, it is also noted that due to the prevailing influence of patriarchy and the oppression of women there is a need to consider women's issues separate from men's, particularly in research (Averett \& Jenkins, 2012) which may also counter some of the invisibility faced by older same-sex oriented women (Traies, 2009). 


\section{Method}

\section{Design}

The present study adopted a qualitative, phenomenological, and idiographic design to enable exploration of older same-sex oriented women who had lost a partner, including these women's personal experiences of loss and how they made sense of these. This focus makes the use of interpretative phenomenological analysis (IPA) appropriate (Smith, Flowers \& Larkin, 2009). In contrast to phenomenological approaches which seek to identify what the essence of a phenomenon is, IPA studies aim to ascertain what the experiences and meanings of a phenomenon are like for a well-defined sample. The approach highlights the importance of individual and personal perceptions and aims to obtain an "insider's view" of the research topic. In contrast to other branches of qualitative inquiry which may seek to explain factors which account for behaviour (e.g., grounded theory) or how people talk about particular topics (such as discursive psychology), IPA is concerned with the sense-making of people who share particular experiences, As in the present study, IPA typically uses semi-structured interviews to explore topics of research interest with participants as this allows the researcher to follow up on interesting and important issues that arise during the interview (see Smith, 2004). Subsequent analysis is centred on identifying thematic areas which describe the central experiences of research interest whilst also elucidating the meanings these experiences generate for participants. The study was approved by the authors' institutional research ethics committee.

\section{Sampling and Participants}

IPA takes an idiographic approach to the study of lived experience and so is concerned with the detailed analysis of specific cases and examining convergence and divergence across cases. Participants are purposively-selected due to their ability to represent 
a particular perspective; for this reason IPA studies typically recruit small samples (samples of 6-10 are common) which are homogenous with regards to the particular parameters of research concern. However, as IPA work is also interested in exploring the variability of participants, it is important that samples are not too uniform (Smith et al., 2009). The decision about how many participants to recruit in IPA work depends on "the degree of commitment to the case study level of analysis, the richness of the individual cases, and the constraints one is operating under" (Smith \& Osborn, 2008: p.56). Given our own aim to balance the idiographic nature of IPA with analysis for a well-defined group, alongside the requirement to provide an in-depth interpretative account, a pragmatic upper limit of ten participants was decided on in advance. The present study was interested in same-sex partner bereavement for older women living within the UK. As an exploratory study, women over the age of 60 (this was deemed to represent 'older age' as it coincided with retirement for most of this cohort), having lived most or all of their life in the UK, and having lost a samesex partner in mid- to late-life were eligible to take part. No upper limit was placed on the time since bereavement.

A large number of organisations including charities, support groups and services with whom older people or the LGBT community might engage were approached via email or telephone contact. Examples include a same-sex oriented women's support group and a community service for older people. Those that agreed to advertise the study were provided with pre-prepared information to forward on to members or service users, or sent posters to display in their services. No individuals were approached directly. Those women who felt they met the inclusion criteria and were interested in taking part contacted the main author, resulting in a self-selected sample.

Eight women took part in semi-structured interviews (see Table 1, pseudonyms used). Participants were aged between 61 and 74, with a mean age of 68.3. Time since the loss 
ranged from 1 year to 6 years, excluding Nancy who had lost her partner 16 years previously. Relationship length prior to the loss ranged from 15 to 48 years, with a mean of 24.9 years. Three of the eight women (37.5\%) were in civil partnerships with the partner they lost. The women were asked to state how they defined their sexual orientation: five women described their sexual orientation as 'lesbian', two as 'gay' and one did not assign a label. All participants described their nationality as British, and had lived in Great Britain (England, Scotland or Wales) for most of their lives. One participant had emigrated to France following retirement.

[Table 1 near here]

\section{Data Collection}

As the primary aim of IPA research is to collect rich, detailed, first-person accounts (Smith et al., 2009), semi-structured, individual interviews were conducted to explore the women's experiences of partner loss, using an interview schedule to guide discussions. The interview schedule was devised in light of previous literature (Bent \& Magilvy, 2006; Fenge, 2014) and amended following the first interview to restructure the order of some questions. Six participants chose to undertake the interviews over the telephone and two preferred faceto-face interviews. Conducting interviews over the telephone does not appear to detrimentally impact on the quality of data (Holt, 2010) and allowed those with mobility difficulties and those located further away to take part. Telephone interviews may also allow for deeper exploration of sensitive or upsetting topics (Novick, 2008), thus ensuring sufficient meaningful data was generated from each interview. Interviews lasted between 60 and 130 minutes (mean: 76.3 minutes), and were digitally recorded. 


\section{Data Analysis}

The data were analysed in line with guidance from Smith et al. (2009) which emphasise: (i) the use of reflexivity to bracket one's preconceptions to avoid these unduly influencing the analysis; (ii) examining the descriptive, conceptual and linguistic nature of the text to elucidate in thematic form both the lived experience of research interest and the meanings of that experience; (iii) conducting analysis transcript-by-transcript to retain the idiographic focus of IPA; and (iv) explicating the areas of commonality and divergence within and across transcripts

Reflexivity, or rather the 'explicit evaluation of the self' (Shaw, 2010, p. 235) is of particular importance in conducting IPA research, due to the recognition that all interpretations will be influenced by the researcher's own beliefs, expectations and experiences (Smith, Jarman \& Osborn, 1999). Recognition of these beliefs and expectations can help in 'bracketing' the researcher's own understandings so as to privilege participants' meanings and experiences. For transparency a summary of these understandings is offered here. The first author (who undertook all interviews) is a same-sex oriented, 27 year old, white British female. Having an alliance with feminist values, the first author was aware of the psychological impact of oppression due to gender, age, or sexual orientation (Bowleg, 2008), and approached the research from this perspective.

All interviews were transcribed by the first author, who repeatedly read these to become familiar with the participants' accounts. An idiographic approach was taken (see Smith, Harré \& Van Langenhove, 1995), whereby each transcript was analysed individually and initial notations were made concerning the descriptive, conceptual and linguistic nature of the text (see Smith et al., 2009). These notes were then used to form emergent themes reflecting the meaning of the participant's account, following which conceptually related emergent themes were clustered together. Once all eight participants' accounts had been 
analysed, the resultant groupings were compared across the whole sample, searching for commonality and divergence. At this point concepts that were novel, and seemed specific to this population were included and clustered into relevant groupings to form superordinate themes. These were then titled to reflect the similarity and variation amongst participants' experiences, and emphasise the different contexts in which their experiences occurred. To enhance validity (e.g. Yardley, 2008) and the quality of the data, all four authors reviewed the data and agreed the emergent and superordinate themes

\section{Results}

The three main themes generated were: (i) 'People didn't come rushing to assist': Being left alone, (ii) 'People saw me as having lost a friend': Navigating visibility, and (iii) 'What you need in that situation is support from other like-minded people, people that are gay': Finding new places to be authentic.

\section{'People didn't come rushing to assist': Being Left Alone}

Participants described their experiences of isolation and exclusion following the loss of their partners. Having lost touch with friends over the years, they had often become isolated prior to the bereavement. For example, Abby described becoming disconnected from the LGBT community with age: 'In later years we'd sort of put the clubbing days and late nights and parties behind us', and felt this was characteristic of older, same-sex relationships. The women had felt content despite this: 'as long as there's two of you [you're okay]' (Liz), but losing their partner induced a sense of loneliness: 'the fact that your other half is gone just highlights how alone you are' (Abby).

The women highlighted a societal expectation that families would be supportive following the loss: 'if some crisis happens like this, people tend to think, "well it's up to your 
family to look after you"' (Liz). However this did not reflect the women's experiences, in fact many of the women lacked supportive family networks. For some this was due to feeling unaccepted by families of origin, leading to strained or distant relationships: 'we had two sets of parents who were completely unable to deal with our relationship. We just mostly ignored them' (Rebecca). For others this lack of support from families of origin was due to their parents and siblings having passed away: 'I haven't got any family at all now ... all her [Rosy's] family had died' (Dee).

Additionally, many were actively excluded from their partner's families following the bereavement: 'they [partner's son and daughter-in-law] brought me home from the funeral and ... just left me at the door and that was it' (Liz). Participants attributed this as due to partners' families not viewing them as valid family members. Being excluded from their partner's family increased distress by multiplying the women's losses, and meant they missed out on grieving rituals such as cremations:

They didn't even tell me she was cremated, I wasn't invited. I went to try and find where she was interred and I couldn't find it, I asked everyone, but they said I needed to ask the family which obviously I wasn't going to do. (Alison).

The sense of isolation and aloneness the women felt following the loss raised concerns about who would look after them as they got older: 'There won't be anybody to look after me in the way I've looked after her' (Dee). This caused significant anxiety for the women who, through losing their partners, were faced with their own mortality, and forced to consider their futures and the impact of being so isolated on their own care needs in later life.

Women without children lacked the support that parent-child relationships could provide, and this also increased the women's sense of disconnection from other women their age following the bereavement, increasing their sense of isolation: 'Not having been married 
and having a family of my own ... I don't have a lot in common with all these family women and grandmothers' (Liz).

Exceptions to this were described by the three women who had adult children from previous relationships: Kate, Harriet and Rebecca. Having children to support them was seen as invaluable: 'My daughter's been truly amazing' (Rebecca). However, the women often described the limitations of support that children could provide and they did not wish to burden their children during their bereavement: 'I know my daughters were there, but ... I didn't want to load them with my issues' (Harriet). Therefore having children reduced feelings of loneliness, but did not necessarily provide the women with emotional support during their bereavement.

\section{'People saw me as having lost a friend': Navigating Visibility}

Participants recounted how invisibility of them and their partner's relationship resulted in their bereavement being misunderstood and invalidated, causing them additional distress. The women described experiencing a lifetime of prejudice: 'we grew up in a world where what we were was despised' (Rebecca). In order to avoid this negative response the women often abstained from explicitly disclosing their sexual orientation and same-sex relationships to professionals as well as to friends and family: 'Neither Sandra nor I felt we could actually say to them [hospice staff] that we were a lesbian couple' (Harriet). In some ways the women felt that this concealment was helpful and adaptive as it minimised anxiety about experiencing prejudice when accessing necessary health care. However this concealment became detrimental when the women were bereaved, as the extent of their grief was not acknowledged: 'they just assumed we were two friends living together ... people saw me as having lost a friend but it was actually much more than that' (Harriet). For some, it 
resulted in their grief being ignored completely: 'A couple of my friends that I go walking with, never said a thing. Never even acknowledged that she'd died.' (Dee).

Others felt people didn't take their grief seriously: 'some people say the most ridiculous bloody comments: "oh you know, you'll soon get over it"' (Abby). This caused significant distress for the women and they sometimes felt anger and disbelief that their grief could be ignored in this way. Even those women who were in civil partnerships reported that although their loss was recognised legally, the grief which accompanied the loss was not always validated socially, such as by acquaintances or neighbours. Although Dee felt upset by her grief being ignored she did not feel surprised, stating: 'I've sort of been used to that all my life you see, that being ignored'.

The women felt that for the most part, society has become much more accepting: ' 30 , 40 years ago it wouldn't have been acknowledged and if it was acknowledged, "well those perverts deserve anything they get"' (Rebecca). Yet there was a sense that subtle prejudice persisted: 'These days you don't see homophobia until something bad happens' (Rebecca). For example, Abby had attended a bereavement support group, but despite feeling it could have been beneficial to her adjustment to the loss, she chose not to return after one session due to other group members' responses: 'I was getting the strong impression they were antigay. Which was not what I needed at that time ... and they all made the assumption it must be my husband that died'. There was a sense that experiencing 'anti-gay' responses during bereavement was particularly difficult as this was a time when they required greater empathy and support, and were less resilient. However, these negative experiences were not universal. For example, Rebecca felt surprised her grief was acknowledged and that she was well supported during her bereavement, after having experienced homophobia previously, : 'the fact that people [family, friends and professionals] .... treated me with respect and gave my relationship the dignity it deserved was beautiful.'(Rebecca). 
The women often navigated visibility earlier in life by seeking to become visible in alternative ways. For example, some were involved in the gay rights and women's liberation movements in an attempt to improve life for other LGBT people. This coping response was also adopted following the bereavement, whereby the women felt a desire to use their bereavement experiences to support other same-sex oriented women in the future; such as by setting up LGBT bereavement support groups (Liz, Abby) and getting involved in advancing social justice (Liz). This was also the main reason the women gave for taking part in the research: 'I just think lesbian women need to be seen as just normal and part of society ... and this research seemed to be getting people heard' (Dee). This enabled the women to feel more seen and heard, thereby reducing their sense of invisibility and exclusion from society, and validating their grief.

\section{'What you need in that situation is support from other like-minded people, people that are gay': Finding New Places to be Authentic}

The need to find new safe spaces to be authentic once their partner had died, to support the grieving process and benefit their futures, was expressed by participants. Having same-sex attractions during a time when this was not readily accepted meant participants felt it necessary to conceal their true identities: 'you can never be completely yourself [with other people]' (Dee). However, partners had provided a relationship in which the women could truly be themselves. The bereavement therefore resulted in the women losing a vital safe space to be authentic: 'I haven't sort of got any being friends, I've just got doing friends now' (Dee), 'It's this not having somebody there to be with. To just $b e$. ' (Harriet). There was a sense that other same-sex oriented women would be the best people to provide this space to be authentic, both during the bereavement and in their futures: 'What you need in that situation is support from other like-minded people, people that are gay' (Harriet). 
Despite a desire to socialise with other same-sex oriented women, participants lacked these social networks: 'We didn't need to go out and socialise with other gay women. I wish we had've done though now' (Harriet). Some women had always lacked this, due to the invisibility of women in same-sex relationships (discussed in theme two): 'lesbian women have been marginalised and leading a, almost a secret life throughout my life' (Dee). Others had previously had these connections, but as they got older they felt disconnected from LGBT community: 'I've spent a lot of my life with a community of like-minded women. Most of whom were lesbians ... I live in a lesbian desert a bit now, that's made it a bit difficult' (Rebecca). This resulted in the women having limited spaces to be authentic once bereaved.

As an alternative or adjunct to seeking out support from other same-sex oriented women, five of the women (Kate, Liz, Abby, Harriet and Nancy) sought formal support from psychological therapists, who would be non-judgemental. This provided them with 'a space to talk, and cry' (Kate) which supported the grieving process: 'the intensity of the grief, it started to ease' (Nancy). For some this therapeutic relationship provided an interim replacement for the relationship that had been lost, which helped adjustment.

Harriet found her safe space with someone who was both a lesbian and a counsellor: 'I had some counselling last year, from a lesbian counsellor ... she was very good at getting me to open up'. Therefore it seemed that finding someone who the women perceived to be accepting and non-judgmental, either due to their personal (being a lesbian) or professional (being a therapist) characteristics provided a vital space to grieve openly and without fear of prejudice.

After the loss, the women actively looked for new friendships with other older, samesex oriented women to take forward into their new futures: 'I joined a couple of websites seeking new friends' (Abby), 'I found this older lesbians group' (Harriet). This also helped 
alleviate the loneliness that was described in theme one. It was sometimes difficult taking this step: 'it took a lot of courage, it wasn't easy, but... they're invaluable' (Harriet). Others sought out new romantic relationships, which they hoped would provide not only a space to be authentic, but also the closeness and loving relationship that had been lost along with their partner. For example, Alison described her desire for a new relationship and the challenges associated with this: 'I'm in the early stages of a relationship ... It's a completely different kind of relationship to what I had with Sandra. I'm still finding it hard to come to terms with somebody else in that sort of situation'. Others expressed a desire for a new relationship but did not think this was a possibility due to their age:

I would hate to think that I'm gonna spend the rest of my life on my own I really don't want that ... I'd like to be in love again and I want to be loved ... But whether it'll happen, hmm, I haven't got age on my side you see. (Harriet).

\section{Discussion}

The aim of this research was to understand and make sense of older women's experiences of same-sex partner bereavement. The main findings which focused on experiences specific to this group, identified three themes where their identities as older same-sex oriented women were salient. These themes suggest that existing theories of bereavement (e.g. the dual process model; Stroebe \& Schut, 2010, and disenfranchised grief; Doka, 1989) may provide useful frameworks when seeking to understand the experiences of older women who have lost their same-sex partners.

The women had experienced social isolation during their bereavement, supporting previous research with this population (Almack et al., 2010; Bent \& Macgilvy, 2006; Fenge, 2014; Jenkins et al., 2014). The detrimental impact of social isolation on adjustment to loss has been widely explored (Schut \& Stroebe, 2010) with theories proposing that social support 
may buffer the effects of bereavement (Lakey \& Cohen, 2000). A lack of social support may therefore alter the grieving process for women who lose same-sex partners. This isolation appeared not only due to the significant social exclusion already faced by this population (Concannon, 2009), but due to the loss of existing sources of support during the bereavement, such as partners' families who actively excluded the women during the bereavement. In addition to reducing their social networks, which may negatively affect psychological wellbeing (Schut \& Stroebe, 2010), losing these other important relationships could further complicate the adjustment process by multiplying the number of losses experienced (Mercer \& Evans, 2005). Multiple losses, particularly those that occur simultaneously, may lead to 'bereavement overload' (Garrett, 1987), due to a lack of separate grieving time for each loss.

It is also common for older same-sex oriented women to have lost, or to be estranged from families of origin (Heaphy, Yip \& Thompson, 2004). Previous research has demonstrated that friends ('families of choice'; Weeks, Heaphy \& Donovan, 2001, p. 9) fill the gap left for LGBT individuals who lack biological family support, yet this was not evident in the current findings, as many of the women also lacked support from friends following the bereavement. It was particularly evident that the women lacked friendships with other same-sex oriented women, due to the invisibility of their older LGBT peers, or perhaps due to anxiety or physical health difficulties in older age (Fees, Martin \& Poon, 1999), which prevented them from seeking out the connections that their younger peers may benefit from. This may have had detrimental effects on the women's psychological wellbeing following bereavement, as links to LGBT community can improve self-esteem (Frable, Platt \& Hoey, 1998), which may buffer against the impact of bereavement (van Baarsen, 2002).

Without links to LGBT community, older women may lack a space to be their authentic selves after losing their same-sex partners. Prior experiences of prejudice or exclusion may lead same-sex oriented women to feel apprehensive about being authentic in 
social relationships (O'Boyle \& Thomas, 1996), making restoration-focused grieving processes more difficult. This may particularly be the case for women of an older generation who have faced prolific homophobia and exclusion earlier in their lives, and experience more internalised homophobia than younger people (Grossman, D'augelli \& O'connell, 2002).

For some, professional therapeutic relationships provided unconditional acceptance of their authentic selves, which can support adjustment to bereavement (Lendrum \& Syme, 1992). This may be particularly helpful for older women who have lost a same-sex partner as an accepting, non-judgmental relationship may provide much-needed validation of their grief and create a space safe to conduct the loss-oriented grief work (Stroebe \& Schut, 2010). LGBT individuals' willingness to engage with formal support services may create a barrier to this, as research suggests many are reluctant to seek out formal support for fear of prejudice or discrimination (Fish, 2010). Yet, the current findings provide an alternative perspective, as many of the women sought formal bereavement support. This could be due to health and social care professionals' increased awareness of diversity issues (Department of Health, 2006), which may have contributed to reducing experiences of prejudice.

The women also experienced 'disenfranchised grief' (Doka, 1989) supporting previous findings with this population (Almack et al., 2010; Jenkins et al., 2014; Fenge, 2014). The disenfranchisement of grief may be a direct result of the women's desire to conceal their relationship or sexual orientation (Deevey, 2000; Fenge, 2014), which resulted in unrecognised relationships (one of the three main categories of invisible losses outlined by Doka, 1989). While the desire to conceal their relationship appears an adaptive attempt to avoid further prejudice, it may prove detrimental to women's experiences of same-sex partner bereavement, as others simply do not understand the importance of the loss. This may alter the adjustment process (Worden, 1991) as the women may be unable to express or seek 
support for their grief. The women may have also been at greater risk of disenfranchised grief due to their age; being older resulted in them being 'unrecognised grievers' (Machin, 2009).

\section{Limitations and Suggestions for Future Research}

The recruitment strategy had both strengths and limitations. Our use of IPA led to selection of a well-defined, homogenous group. Analysis centred on gaining a complete and rich (i.e., detailed and interpretative) representation of the data obtained for this particular group. This is because while IPA is not opposed to more general claims for larger populations, it is "committed to the painstaking analysis of cases rather than jumping to generalisations" (Smith \& Osborn, 2008, p. 54). Although generalisable claims regarding a sample in a single IPA study are not made, as more studies with other samples are carried out with similar findings, more general claims become possible. Smith and Osborn (2008) refer to this as "theoretical generalisability," rather than "empirical generalisability."

Using purposive sampling to recruit individuals who are largely invisible within society may result in a fundamental selection bias in that only those willing to define themselves in this way came forward to take part (Grossman, D'Augelli \& Hershberger, 2000), therefore the experiences of the most isolated individuals who conceal their identities are more difficult to explore. Participatory research designs may increase the accessibility of invisible groups (Stewart \& Bhagwanjee, 1999), and could be considered for future research in this area, although further consideration is needed regarding how to include particularly isolated and invisible individuals, whilst homophobic and heteronormative discourses persist.

The sample included here were fairly homogenous; all reported to be White British and either Christian, atheist or agnostic. Ethnicity and faith may impact upon experiences of bereavement (Becker et al., 2007), and so future research could consider the experiences of those with other religious beliefs, and those from black and minority ethnic (BME) groups. 
Furthermore, the women included here were all under 75, and so the experiences of older-old women who have lost a same-sex partner remain unexplored (Averett \& Jenkins, 2012). Additionally, none of the participants defined themselves as bisexual so the experiences of bisexual older women who have lost a same-sex partner remain mostly unexplored. Although there may be additional barriers to recruiting these particularly marginalised groups (Ali, 1992; McMurdo et al., 2011), ignoring these experiences in research could further contribute to the oppression they may face.

\section{Clinical Implications}

The UK National Institute for Clinical Excellence (2004) guidance on improving supportive and palliative care for adults with cancer suggests a model of bereavement support with three levels (with applicability for many experiences of loss, not just from cancer). The first level includes provision of information about the experience of bereavement and signposting to other forms of support, as well as that provided by family and friends, the second level is more formalised bereavement support from volunteer organisations and community groups and the third level involves professional input, including from psychologists, psychotherapists and counselling services. At each of these levels the needs of older women who have lost a same-sex partner need consideration.

A recent report into the treatment of LGBT individuals in health and social care services in the UK (Stonewall, 2015) suggested that up to a quarter of staff are not confident in addressing the needs of LGBT people and a similar number had never received any inclusivity and diversity training, including the use of appropriate language. Such training is vital in addressing the needs of same sex-oriented women at a time of bereavement to avoid heterocentric assumptions and language both in personal interactions and in provided materials (Concannon, 2009; McNair \& Hegarty, 2010; Valenti \& Katz, 2014). More 
specifically, ensuring health and social care providers understand the experiences of samesex partner loss in later life may help them consider more fully appropriate signposting (e.g. at level one) and reduce the fear of stigmatisation that prevents many same-sex oriented women from accessing formal support (level three; Fish \& Bewley, 2010).

At level two facilitated social activities for older women may increase social inclusion (Windle, Francis \& Coomber, 2011), although these risk being heterocentric, ignoring the specific experiences of older women who have lost a same-sex partner (Milenkovic, 2015). Groups specifically for older women who have lost a same-sex partner, or women's groups which carefully consider diversity issues may enable these individuals to develop social support networks with the additional benefit of providing a safe space to be authentic with like-minded peers. Research suggests these kinds of bereavement groups would be desirable to same-sex oriented women (Jacobs, Rasmussen \& Hohman, 1999).

Further avenues for intervention at level three may consist of psychotherapeutic work within counselling or other bereavement therapies. This may provide bereaved same-sex oriented women with a vital space to be authentic, in addition to offering an opportunity to work through and process grief (Jordan \& Neimeyer, 2003). Access to these types of interventions may be particularly valuable for those who experience disenfranchised grief (Worden, 2009).

While direct therapeutic interventions may be useful for women who have lost a same-sex partner, it is suggested that greater change can be achieved if interventions focus on changing societal discourses in order to enhance inclusion of LGBT individuals (Green, 2007). Indeed, with research increasingly highlighting the links between social inequality and distress (Pickett \& Wilkinson, 2015), greater emphasis should be placed on health and social care providers' role in contributing to advancing social justice in order to enhance wellbeing 
(White, 2008). Therefore, these findings suggest that through challenging homophobic, heterosexist and ageist narratives, the psychological wellbeing of older women who lose a same-sex partner can be enhanced as these narratives arguably contribute to the exclusion and marginalisation of this group. These forms of interventions could include diverse curricula within education, effective campaigning, inputting into policy guidance and development, and promotion of intergroup contact and cohesive communities (Abrams, 2010).

\section{Conclusions}

The findings support previous literature and offer novel insights into the experiences of older women who have lost a same-sex partner. It appears that these women may face social isolation and the loss of a safe space to be authentic, which can impact upon their adjustment to the loss of their partner. Considerations for professionals working with older women who have lost a same-sex partner include the importance of promoting social inclusion, and the value of increasing understanding of the issues unique to these women. Further societal shifts are needed, largely tackling homophobic and heterosexist discourses within UK culture, if greater improvements in the experiences of older women who lose a same-sex partner are to be made. 


\section{References}

Abrams, D. (2010). Processes of prejudices: Theory, evidence and intervention. Technical report. London: Equalities and Human Rights Commission.

Ali, Y. (1992). Muslim women and the politics of ethnicity and culture in Northern England. Refusing holy orders: women and fundamentalism in Britain, 101-123.

Almack, K., Seymour, J., \& Bellamy, G. (2010). Exploring the impact of sexual orientation on experiences and concerns about end of life care and on bereavement for lesbian, gay and bisexual older people. Sociology, 44(5), 908-924. doi:

\section{$10.1177 / 0038038510375739$}

Averett, P., \& Jenkins, C. (2012). Review of the literature on older lesbians implications for education, practice, and research. Journal of Applied Gerontology, 31(4), 537-561. doi: $10.1177 / 0733464810392555$

Becker, G., Xander, C. J., Blum, H. E., Lutterbach, J., Momm, F., Gysels, M., \& Higginson, I. J. (2007). Do religious or spiritual beliefs influence bereavement? A systematic review. Palliative Medicine, 21(3), 207-217. doi: 10.1177/0269216307077327

Bellamy, G., Gott, M., Waterworth, S., McLean, C., \& Kerse, N. (2014). 'But I do believe you've got to accept that that's what life's about': Older adults living in New Zealand talk about their experiences of loss and bereavement support. Health \& Social Care in The Community, 22(1), 96-103. doi:10.1111/hsc.12069

Bennett, K. M. (1997). Widowhood in elderly women: The medium-and long-term effects on mental and physical health. Mortality, 2(2), 137-148. doi: 10.1080/713685857

Bennett, K. M. (1998). Longitudinal changes in mental and physical health among elderly, recently widowed men. Mortality, 3(3), 265-273. doi: 10.1080/713685953

Bennett, K. M., \& Vidal-Hall, S. (2000). Narratives of death: a qualitative study of widowhood in later life. Ageing and Society, 20(04), 413-428. 
Bent, K. N., \& Magilvy, J. K. (2006). When a partner dies: Lesbian widows. Issues in Mental Health Nursing, 27(5), 447-459. doi: 10.1080/01612840600599960

Bergman, E. J., \& Haley, W. E. (2009). Depressive symptoms, social network, and bereavement service utilization and preferences among spouses of former hospice patients. Journal of Palliative Medicine, 12(2), 170-176. doi:10.1089/jpm.2008.0237.

Bowlby, J. (1980). Loss: Sadness and depression (Attachment and loss, Vol. 3). New York: Basic Books.

Bowleg, L. (2008). When Black+ lesbian+ woman $\neq$ Black lesbian woman: The methodological challenges of qualitative and quantitative intersectionality research. Sex roles, 59(5-6), 312-325. doi: 10.1007/s11199-008-9400-z

Concannon, L. (2009). Developing inclusive health and social care policies for older LGBT citizens. British Journal of Social Work, 39(3), 403-417. doi: 10.1093/bjsw/bcm131

Deevey, S. (2000). Cultural variation in lesbian bereavement experiences in Ohio. Journal of the Gay and Lesbian Medical Association, 4(1), 9-17. doi:

10.1023/A:1009526210103

Department of Health (2006). Our health, our care, our say: a new direction for community services. London: DH Publications.

Doka, K. J. (1989). Disenfranchised grief: Recognizing hidden sorrow. Lexington, MA: Lexington Books.

Fees, B. S., Martin, P., \& Poon, L. W. (1999). A model of loneliness in older adults. The Journals of Gerontology Series B: Psychological Sciences and Social Sciences, 54(4), 231-239. doi: 10.1093/geronb/54B.4.P231 
Fenge, L. A. (2014). Developing understanding of same-sex partner bereavement for older lesbian and gay people: Implications for social work practice. Journal of Gerontological Social Work, 57(2-4), 288-304. doi: 10.1080/01634372.2013.825360

Fish, J. (2010). Conceptualising social exclusion and lesbian, gay, bisexual, and transgender people: the implications for promoting equity in nursing policy and practice. Journal of Research in Nursing, 15(4), 303-312. doi: 10.1177/1744987110364691

Fish, J., \& Bewley, S. (2010). Using human rights-based approaches to conceptualise lesbian and bisexual women's health inequalities. Health \& Social Care in the Community, 18(4), 355-362. doi:10.1111/j.1365-2524.2009.00902.x।

Frable, D. E., Platt, L., \& Hoey, S. (1998). Concealable stigmas and positive self-perceptions: feeling better around similar others. Journal of Personality and Social Psychology, 74(4), 909. doi: 10.1037/0022-3514.74.4.909

Freud, S. (1917/1957). Mourning and Melancholia. In J. Strachey (Ed.) The standard efition of the complete works of Sigmund Freud (Vol. 14, pp. 152-170). London: Hogarth Press.

Garrett, J. E. (1987). Multiple losses in older adults. Journal of Gerontological Nursing, 13(8), 8-9.

Gillies, J., \& Neimeyer, R. A. (2006). Loss, grief, and the search for significance: Toward a model of meaning reconstruction in bereavement. Journal of Constructivist Psychology, 19(1), 31-65. doi: 10.1080/10720530500311182

Green, R. J. (2007). Gay and lesbian couples in therapy: A social justice perspective. In E. Aldarondo (Ed.), Advancing social justice through clinical practice (pp. 119-149). Mahwah, NJ: Lawrence Erlbaum.

Grossman, A. H., D'Augelli, A. R., \& Hershberger, S. L. (2000). Social support networks of lesbian, gay, and bisexual adults 60 years of age and older. The Journals of 
Gerontology Series B: Psychological Sciences and Social Sciences, 55(3), 171-179. doi: 10.1093/geronb/55.3.P171

Grossman, A. H., D'Augelli, A. R., \& O'connell, T. S. (2002). Being lesbian, gay, bisexual, and 60 or older in North America. Journal of Gay \& Lesbian Social Services, 13(4), 23-40. doi: 10.1300/J041v13n04_05

Hansson, R. O., \& Stroebe, M. S. (2007). Bereavement in late life: Coping, adaptation, and developmental influences. Washington, DC: American Psychological Association.

Hawthorne, G. (2006). Measuring social isolation in older adults: development and initial validation of the Friendship Scale. Social Indicators Research, 77(3), 521-548. doi: $10.1007 / \mathrm{s} 11205-005-7746-\mathrm{y}$

Heaphy, B., Yip, A. K., \& Thompson, D. (2004). Ageing in a non-heterosexual context. Ageing and Society, 24(06), 881-902. doi: 10.1017/S0144686X03001600

Herek, G. M. (2004). Beyond "homophobia": Thinking about sexual prejudice and stigma in the twenty-first century. Sexuality Research \& Social Policy, 1(2), 6-24. doi: 10.1525/srsp.2004.1.2.6

Holt, A. (2010). Using telephones for narrative interviewing: a research note. Qualitative Research, 10, 113-121. doi: 10.1177/1468794109348686

Jacobs, R. J., Rasmussen, L. A., \& Hohman, M. M. (1999). The social support needs of older lesbians, gay men, and bisexuals. Journal of Gay \& Lesbian Social Services, 9(1), 130. doi: 10.1300/J041v09n01_01

Jenkins, C. L., Edmundson, A., Averett, P., \& Yoon, I. (2014). Older lesbians and bereavement: Experiencing the loss of a partner. Journal of Gerontological Social Work, 57(2-4), 273-287. doi: 10.1080/01634372.2013.850583

Jordan, J. R., \& Neimeyer, R. A. (2003). Does grief counseling work?. Death Studies, 27(9), 765-786. doi:10.1080/713842360 
Kübler-Ross, E. (1975). On death and dying. Bulletin of the American College of Surgeons, 60(6), 12-15.

Lakey, B., \& Cohen, S. (2000). Social support theory and measurement. In S. Cohen, L. G. Underwood \& B. H. Gottlieb (Eds.), Social support measurement and intervention: A guide for health and social scientists (pp. 29-52). New York: Oxford University Press

Lendrum, S., \& Syme. G. (1992). Gift of Tears: A Practical Approach to Loss and Bereavement Counselling. London: Routledge

Lobb, E. A., Kristjanson, L. J., Aoun, S. M., Monterosso, L., Halkett, G. K., \& Davies, A. (2010). Predictors of complicated grief: A systematic review of empirical studies. Death Studies, 34(8), 673-698. doi: 10.1080/07481187.2010.496686

Machin, L. (2009). Working with loss and grief: A new model for practitioners. London: Sage.

McMurdo, M. E., Roberts, H., Parker, S., Wyatt, N., May, H., Goodman, C., Jackson, S., Gladman, J., O'Mahony, S., Alis, K., Dickinson, E., Edison, P. \& Dyer, C. (2011). Improving recruitment of older people to research through good practice. Age and Ageing, 40(6), 659-665. doi: 10.1093/ageing/afr115

McNair, R. P., \& Hegarty, K. (2010). Guidelines for the primary care of lesbian, gay, and bisexual people: a systematic review. The Annals of Family Medicine, 8(6), 533-541. doi: 10.1370/afm.1173.

Mercer, D. L., \& Evans, J. M. (2006). The impact of multiple losses on the grieving process: An exploratory study. Journal of Loss and Trauma,11(3), 219-227. doi: $10.1080 / 15325020500494178$ 
Milenkovic, S. (2015). "The Same Yet Different": A review of the evidence of the needs of older lesbian, gay, bisexual and transgender (LGBT) people and access to Health and Social Care Services. Evaluation Support Scotland.

Monk, D. (2011). Challenging homophobic bullying in schools: The politics of progress. International Journal of Law in Context, 7(02), 181-207. doi: $10.1017 / \mathrm{S} 1744552311000061$

Moss, M. S., Moss, S. Z., \& Hansson, R. O. (2001). Bereavement and old age. In M. S. Stroebe, R. O. Hanson, W. Stroebe, \& H. Schut (Eds.) Handbook of Bereavement Research. Consequences, Coping and Care, (pp. 241-260). American Psychological Association, Washington, DC.

Murray, C. Parkes, C. M., \& Prigerson, H. G. (2010). Bereavement: Studies of grief in adult life. London, Penguin.

Musingarimi, P. (2008). Health Issues Affecting Older Gay, Lesbian and Bisexual People in the UK: a policy brief. London: International Longevity Centre.

Naef, R., Ward, R., Mahrer-Imhof, R., \& Grande, G. (2013). Characteristics of the bereavement experience of older persons after spousal loss: An integrative review. International journal of Nursing Studies, 50(8), 1108-1121. doi: 10.1016/j.ijnurstu.2012.11.026

National Institute for Clinical Excellence (2004). Improving supportive and palliative care for adults with cancer. NICE guidance [CSG4]. Available at https://www.nice.org.uk/guidance/csg4

Novick, G. (2008). Is there a bias against telephone interviews in qualitative research?. Research in Nursing \& Health, 31(4), 391-398. doi: 10.1002/nur.20259

O’Boyle, C. G., \& Thomas, M. D. (1996). Friendships between lesbian and heterosexual women. In J. S. Weinstock \& E. D. Rothblum (Eds.), Lesbian friendships: For 
ourselves and each other. The cutting edge: Lesbian life and literature, (pp. 240-48). New York, US: New York University Press.

Parkes, C. M. (1970). The first year of bereavement: A longitudinal study of the reaction of London widows to the death of their husbands. Psychiatry, 33(4), 444-467.

Windle, K., Francis, J., \& Coomber, C. (2011). Preventing loneliness and social isolation: interventions and outcomes. London: Social Care Institute for Excellence.

Schut, H., \& Stroebe, M. (2010). Effects of support, counselling and therapy before and after the loss: can we really help bereaved people?.Psychologica Belgica, 50(1-2). doi: $10.5334 / \mathrm{pb}-50-1-2-89$

Shaw, R. L. (2010). Embedding reflexivity within experiential qualitative psychology. Qualitative Research in Psychology, 7(3), 233- 243. doi: $10.1080 / 14780880802699092$

Smith, J. A. (1995), Semi-structured interviewing and qualitative analysis. In J. A. Smith, R. Harre \& L. van Langenhove (Eds.), Rethinking methods in psychology (pp. 9-26). London: Sage.

Smith, J. A. (2004). Reflecting on the development of interpretative phenomenological analysis and its contribution to qualitative research in psychology. Qualitative Research in Psychology, 1, 39-54.

Smith, J.A. Harré, R., \& Van Langenhove, L. (1995). Idiography and the case study. In: J. A. Smith, R. Harré \& L. Van Langenhove (Eds.) Rethinking psychology. London: Sage. Smith, J. A, Flowers, P., \& Larkin, M. (2009) Interpretative phenomenological analysis: Theory, methods and research. London: Sage. 
Smith, J. A., Jarman, M., \& Osborn, M. (1999). Doing interpretative phenomenological analysis. In M. Murray \& K. Chamberlain (Eds.), Qualitative Health Psychology: Theories and Methods (pp. 218-240). London: Sage.

Smith, J. A. \& Osborn, M. (2008). Interpretative phenomenological analysis, in J. A. Smith (Ed.), Qualitative Psychology: A practical guide to research methods (pp. 53-80). London: Sage.

Stewart, R., \& Bhagwanjee, A. (1999). Promoting group empowerment and self-reliance through participatory research: a case study of people with physical disability. Disability and Rehabilitation, 21(7), 338-345. doi:

$10.1080 / 096382899297585$

Stonewall (2015). Unhealthy Attitudes: The treatment of LGBT people within health and social care services. London: Stonewall. Available from http://www.stonewall.org.uk/sites/default/files/unhealthy_attitudes.pdf

Stroebe, M. S. \& Schut, H. (1999). The dual process model of coping with bereavement: Rationale and description. Death studies, 23(3), 197-224. doi: $10.1080 / 074811899201046$

Stroebe, M., \& Schut, H. (2010). The dual process model of coping with bereavement: A decade on. OMEGA- Journal of Death and Dying, 61(4), 273-289. doi: 10.2190/OM.61.4.b

Stroebe, W., Schut, H., \& Stroebe, M. S. (2005). Grief work, disclosure and counseling: Do they help the bereaved?. Clinical Psychology Review, 25(4), 395-414. doi:10.1016/j.cpr.2005.01.004

Stroebe, M. S., Schut, H., \& Stroebe, W. (2007). Health outcomes of bereavement. The Lancet, 370(9603), 1960-73. doi:10.1016/S0140-6736(07)61816-9 
Traies, J. E. (2009). Now you see me: The invisibility of older lesbians. (MPhil dissertation, University of Birmingham).

Valenti, K., \& Katz, A. (2014). Needs and perceptions of LGBTQ caregivers: the challenges of services and support. Journal of Gay \& Lesbian Social Services, 26(1), 70-90. doi: $10.1080 / 10538720.2013 .865575$

Van Baarsen, B. (2002). Theories on coping with loss the impact of social support and selfesteem on adjustment to emotional and social loneliness following a partner's death in later life. The Journals of Gerontology Series B: Psychological Sciences and Social Sciences, 57(1), 33-42. doi: 10.1093/geronb/57.1.S33

Weeks, J., Heaphy, B., \& Donovan, C. (2001). Same sex intimacies: Families of choice and other life experiments. London: Routledge.

White, J. (2008). Stepping up primary care. The Psychologist, 21, 844-847. Available from https://thepsychologist.bps.org.uk/volume-21/edition-10/stepping-primary-care

Worden, W. J. (1991). Grief Counselling and Grief Therapy. London: Routledge.

Worden, W. J. (1996). Children and Grief: When a Parent Dies. New York: Guildford.

Worden, W. J. (2009). Grief counseling and grief therapy: A handbook for the mental health practitioner (4th edition). New York: Springer.

Yardley, L. (2008). Demonstrating validity in qualitative psychology. In J. A. Smith (Ed.), Qualitative psychology. A practical guide to research methods (pp. 234-251). London: Sage. 
Table 1. Participant Characteristics

\begin{tabular}{|c|c|c|c|c|c|c|}
\hline Name $^{1}$ & $\begin{array}{l}\text { Current } \\
\text { age (age } \\
\text { at loss) }\end{array}$ & $\begin{array}{l}\text { Sexual } \\
\text { orientation }\end{array}$ & $\begin{array}{l}\text { Partner's } \\
\text { name } \\
\text { (age at } \\
\text { death if } \\
\text { known) }\end{array}$ & $\begin{array}{l}\text { Length of } \\
\text { relationship } \\
\text { (years) }\end{array}$ & $\begin{array}{l}\text { Reason } \\
\text { for } \\
\text { partner's } \\
\text { death }\end{array}$ & $\begin{array}{l}\text { Mode of } \\
\text { interview }\end{array}$ \\
\hline Abby & $61(60)$ & Gay & Jo (58) & 37 & $\begin{array}{l}\text { Alcohol } \\
\text { related }\end{array}$ & Telephone \\
\hline Alison & $69(66)$ & Gay & Lily (90) & 16 & $\begin{array}{l}\text { Chest } \\
\text { infection }\end{array}$ & Telephone \\
\hline Dee & $74(72)$ & Lesbian & Rosy & 48 & Dementia & In person \\
\hline Harriet & $68(65)$ & Lesbian & $\begin{array}{l}\text { Sandra } \\
\text { (77) }\end{array}$ & 25 & $\begin{array}{l}\text { COPD }^{2} \\
\& \\
\text { bowel } \\
\text { cancer }\end{array}$ & Telephone \\
\hline Kate & $63(59)$ & Lesbian & $\begin{array}{l}\text { Barbara } \\
\text { (61) }\end{array}$ & 15 & Cancer & Telephone \\
\hline Liz & 73 (69) & Undefined & Jen & 25 & $\begin{array}{l}\text { Lung } \\
\text { cancer }\end{array}$ & In person \\
\hline Nancy & $70(53)$ & Lesbian & $\begin{array}{l}\text { Hannah } \\
\text { (38) }\end{array}$ & 15 & $\begin{array}{l}\text { Breast } \\
\text { cancer }\end{array}$ & Telephone \\
\hline Rebecca & $68(62)$ & Lesbian & $\begin{array}{l}\text { Natalie } \\
(60)\end{array}$ & 18 & $\begin{array}{l}\text { Road } \\
\text { traffic } \\
\text { accident }\end{array}$ & Telephone \\
\hline
\end{tabular}

\footnotetext{
${ }^{1}$ Names of participants and their partners have been changed to protect anonymity

${ }^{2}$ Chronic Obstructive Pulmonary Disease
} 